\title{
The Influence of University Teachers' Scientific Research Pressure on Scientific Research Performance, Job Satisfaction, Mediation and Adjustment of Emotional Intelligence
}

\author{
Wei Guorong \\ Dept. of Management, Limkokwing University of Creative Technology \\ Jalan Teknokrat 1/1, Cyberjaya, 63000 Cyberjaya, Malaysia
}

Tel: 601-0811-7376Ｅ-mail:wgr668@163.com

Received: June 18, 2019

Accepted: July 4, 2019

Published: July 22, 2019

doi:10.5296/ijmis.v4i1.14943

URL: https://doi.org/10.5296/ijmis.v4i1.14943

\begin{abstract}
How the research pressure of university teachers affects scientific research performance is an important issue in the current development of university teachers and scientific research management. On the basis of literature research, the relationship between job satisfaction and emotional intelligence as intermediaries and adjustment variables was introduced into the relationship between scientific research pressure and scientific research performance, and empirical research was conducted in the form of questionnaires. The following conclusions were drawn: Higher research pressure; scientific research pressure will have a certain negative impact on scientific research performance; scientific research pressure affects scientific research performance through job satisfaction intermediary; emotional intelligence can effectively positively regulate the impact of scientific research pressure on scientific research performance. On this basis, it puts forward some countermeasures to reduce stress sources, optimize scientific research and assessment system, improve salary and treatment, and cultivate emotional intelligence.
\end{abstract}

Keywords: University teachers, Research pressure, Scientific research performance, Emotional intelligence, Job satisfaction 


\section{Introduction}

University is a place to study advanced knowledge. Academic nature is the fundamental characteristic of university, and academic activities are the fundamental activities of university. In the words of Karl Theodor Jaspers, "University is a palace for research and teaching of science, a world for educating new people, a world full of life communication between individuals, and a world full of academic prosperity." In other words, since the reform of Wilhelm VOR Humboldt in Germany, scientific research has been formally established as the second function of universities, and universities have become the focus of scientific research. Therefore, more and more universities regard scientific research performance as an important indicator of their reform and development. At present, under the realistic background of "double first-class" construction, the promotion of university scientific research and the realization of first-class scientific research level are the most important, because "for the construction of first-class universities and current disciplines, engaging in scientific research is an important mission and responsibility, and also the foundation for universities and disciplines to settle down". However, as far as university teachers engaged in scientific research are concerned, the high-intensity scientific research requirements have caused tremendous pressure on scientific research, especially for young university teachers. A survey of young university teachers' work stress in 2011 shows that "scientific research tasks" have become the primary cause of young teachers' stress, with the proportion as high as $72.1 \%$. Pressure on scientific research tends to make teachers feel unfair in their profession, reduce their job satisfaction and happiness, and ultimately affect their scientific research performance.

Then, how does scientific research pressure affect scientific research performance? How does it work? Is there any influencing factor between the two? Current researchers often put forward solutions by analyzing the sources of scientific research pressure or the causes of scientific research pressure. However, we believe that empirical research is still unable to deeply touch the deep-seated impact relationship, especially the path relationship between the two. Therefore, this paper attempts to introduce two variables, job satisfaction and emotional intelligence, into the research of scientific research pressure and scientific research performance through innovative research design, and comprehensively analyze the mechanism of the impact between the two variables.

\section{Literature Review and Research Hypothesis}

\subsection{Research Pressure and Research Performance of University Teachers}

Stress is often defined as "an individual's awareness of the response of the outside world to its demands beyond its capacity to withstand". University teachers' scientific research pressure mainly refers to a series of physiological and psychological comprehensive reactions produced by University teachers' subjective awareness that the requirements of scientific research work are beyond their ability to withstand. Lodahl and Kejner believe that the so-called research pressure refers to the physical or psychological adverse effects of certain factors on researchers in the established research work situation. There are different views on the relationship between job stress and job performance. Gilboa and Shiron believe that stress 
has a negative impact on performance. Of course, some scholars believe that different types of stress have different effects on performance. For example, Ji Xiaoli and others divide stress into two types: endogenous and exogenous, and think that endogenous stress has a positive impact on performance, while exogenous stress has a negative impact on performance. However, according to the current situation of scientific research in China's universities, despite the increasing pressure of scientific research, the total number of various forms of scientific research achievements has been greatly improved, but the overall scientific research performance has not been improved correspondingly. The reason is that the quality of scientific research achievements, as one of the important indicators to measure the performance of scientific research, has not yet reached the desired requirements. This shows that the current research pressure of university teachers in China may exceed the affordable range, and this high-intensity pressure will not only make teachers "light weight", but also may lead to teachers' corresponding research burnout, thus affecting the overall scientific research performance. Accordingly, this paper makes the following assumptions:

H1: University teachers' scientific research pressure has a negative impact on scientific research performance

\subsection{The Mediating Effect of Job Satisfaction on University Teachers' Research Pressure and Research Performance}

Job satisfaction is an individual's subjective feelings and attitudes, which is mainly manifested in the individual's subjective satisfaction with the content, environment, relationship and salary of their own work. Researchers at home and abroad have done a lot of research on the relationship between job stress and job satisfaction from different fields, but most of the research conclusions prove that job stress and scientific research performance are negatively correlated. For example, Boudreaux and Brantley found that there was a significant negative correlation between job stress and job satisfaction. The greater the stress, the lower the satisfaction. Xu Xiaodong, a Chinese scholar, took knowledge workers as subjects and found that job stress had a significant negative impact on job satisfaction. In addition, there are a lot of studies on the relationship between job satisfaction and job performance in academic circles, and the relationship between the two is still inconclusive. Early Mayo, George Elton and Frederick Herzberg considered that job satisfaction was positively correlated with job performance from the perspective of employee morale and psychological needs. Some studies in China have also confirmed this point. Especially for the research work of University teachers, the lack of a good working atmosphere and working environment as a guarantee will inevitably affect the enthusiasm of scientific research work. From the point of view of the current career of University teachers, high-level scientific research results are required for both evaluation and promotion. The resulting research pressure makes teachers in a state of anxiety for a long time and reduces their satisfaction with their work. At the same time, the decline of job satisfaction also causes teachers to have the idea of quick success and instant benefit or a strong sense of job burnout, which reduces the level of scientific research performance. Therefore, this paper proposes the following assumptions: 


\section{Mll Macrothink}

International Journal of Management Innovation Systems

ISSN 1943-1384

2019, Vol. 4, No. 1

$\mathrm{H} 2$ : There is a negative correlation between University teachers' research pressure and job satisfaction.

H3: The job satisfaction of university teachers is positively correlated with scientific research performance.

H4: Job satisfaction plays a mediating role between research pressure and research performance

\subsection{The Moderating Effect of Emotional Intelligence on the Relationship between University} Teachers' Research Pressure and Research Performance

Emotional intelligence reflects an individual's comprehensive emotional management ability, which reflects the individual's behavior through emotional cognition, evaluation or management of self and others. Historically, American psychologists Maver and Salovy first put forward the concept of emotional intelligence, and after several revisions, they finally defined it as "similar to social ability but different from traditional intelligence, which is an individual's ability to effectively recognize, evaluate, manage and control his or her own and other people's emotions". Later, emotional intelligence has gradually been widely used in sociology, management, psychology, pedagogy and other fields. Researchers have done a lot of research on it from different perspectives. Among them, the conclusion on the impact of emotional intelligence on job performance basically confirms the close relationship between the two. In other words, many studies have shown that individual emotional intelligence has a positive impact on job performance. For example, Tram and O'Hara found that there are differences in employees' work performance on the emotional intelligence level. Highly emotional intellectuals can more effectively regulate their own emotions and mentality, have strong confidence and ability to overcome difficulties and resistance, so their work performance is also higher. Through meta-analysis of the relationship between emotional intelligence and job performance, Chinese scholar Zhang Huihua and others found that emotional intelligence can explain $28 \%$ of the variables of job performance. In addition, researchers also found that the impact of emotional intelligence is usually reflected in the individual's stress state. According to King and Gardner's research, emotional intellectuals can better control the negative emotional response in the stress state, and take appropriate actions to alleviate the tension and anxiety caused by stress, which is conducive to better performance at work. Similarly, university teachers with high emotional intelligence can better cope with scientific pressure and minimize the negative impact of scientific research pressure on scientific research performance. Therefore, this paper proposes the following hypothesis:

H5: Emotional Intelligence of University Teachers has a Positive Impact on Research Achievements

H6: Emotional intelligence plays a positive moderating role in the relationship between research pressure and research performance. 


\section{Design of Research and Measurement of Variables}

\subsection{Questionnaire Release and Sample Distribution}

In this paper, teachers specializing in teaching and scientific research in universities are taken as subjects (excluding staff in administrative, teaching and assistant, management and other posts). Eight colleges and universities in Jiangxi and Fujian Province (cluster random sampling method) were selected, and 400 questionnaires were distributed in combination with e-mail distribution. 350 questionnaires were actually recovered, of which 324 were valid, with an effective recovery rate of $81 \%$. The background of the sample is as follows: 211 male teachers (65.1\%), 113 female teachers (34.9\%), 63 male teachers (19.4\%), 105 Vice-Senior teachers $(32.5 \%), 119$ middle-level teachers $(36.7 \%)$, 37 junior teachers $(11.4 \%)$, more middle-level teachers and Vice-Senior teachers, accounting for about $70 \%$ of the total: 50 under 30 years of age (15.4\%), 152 between 30 and 39 years of age (47.0\%), 86 between 40 and 49 years of age $(26.5 \%), 36$ over 50 years of age $(11.1 \%)$. About $74 \%$ of them are aged 49: $104(32.1 \%)$ have undergraduate degree, $144(444 \%)$ have master degree and $76(23.5 \%)$ have doctoral degree. At the academic level, most of them have master degree, followed by undergraduate degree and finally doctoral degree.

\subsection{Variable Selection and Measurement}

This paper involves four main variables. In order to ensure the reliability and validity of the questionnaire as far as possible, the design of the questionnaire draws on the relevant scales at home and abroad. The scientific research stress scale refers to the questionnaire compiled by Dr. Zhang Guiping, which has two dimensions and 14 items: the scientific research performance scale refers to the questionnaire compiled by Dr. Wang Xianya and others, and has eight items: the job satisfaction scale refers to the questionnaire compiled by Dr. Guo Ai, and is modified to form a questionnaire containing 10 items: the emotional intelligence scale refers to the questionnaire compiled by Professors Wong and Law of CUHK, with a total of 4 dimensions and 16 items. (Including the recognition of self-emotion, the understanding of others'emotion, the control and application of self-emotion, etc.). All the four questionnaires were scored by Richter's five-point method. Five points indicated "complete conformity" and one point indicated "complete non-conformity".

\section{Data Statistics and Analysis}

\subsection{Reliability and Validity of Questionnaires}

The reliability test of the questionnaire uses SPSS2.0 statistical software to analyze the intrinsic reliability of the four variables, that is, to calculate the value of Cranach's alpha. The validity test of the questionnaire uses AMOS17.0 software to carry out confirmatory factor analysis to analyze the structural validity of the four variables. From Table 1, we can see that the Crange's alpha of the four variables exceeds the critical value of 0.70 , which indicates that the four scales have high reliability. At the level of structural validity, three fitting indices, absolute, relative and concise, are used to judge the validity. Among them, x/df, RM-SEA and GFI belong to absolute fitting index, CFI and TLI belong to relative fitting index, and PNFI belong to simple fitting index. In the ratio of chi-square to degree of freedom, only the job 
satisfaction variable is between 3 and 5, and the other variables are less than 3: In the square root of approximate error, except the scientific research performance variable is between 0.05 and 0.08, the other variables are less than 0.05: In the goodness-of-fit index, goodness-of-fit index and goodness-of-fit index, the values of all variables reach the critical value. Standards. It can be seen that the fitting indices of the four variables shown in Table 1 have reached acceptable critical values, and some of the fitting indices of some variables have reached an ideal state, that is, they have good validity.

Table 1. Reliability and validity analysis of variable measurements

\begin{tabular}{|l|c|c|c|c|c|c|c|}
\hline & \multicolumn{3}{|c|}{ Reliability Analysis } & \multicolumn{4}{c|}{ Validity test } \\
\cline { 2 - 9 } & Cranach's $\alpha$ & $\mathrm{x}^{2} / \mathrm{df}$ & RM-SEA & GFI & CFI & NFI & PNFI \\
\hline Research Pressure & 0.862 & 2.65 & 0.04 & 0.92 & 0.94 & 0.93 & 0.60 \\
\hline Job satisfaction & 0.823 & 3.04 & 0.05 & 0.95 & 0.95 & 0.90 & 0.61 \\
\hline Emotional Intelligence & 0.914 & 2.58 & 0.04 & 0.93 & 0.95 & 0.91 & 0.58 \\
\hline $\begin{array}{l}\text { Scientific Research } \\
\text { Performance }\end{array}$ & 0.847 & 2.13 & 0.06 & 0.90 & 0.96 & 0.93 & 0.53 \\
\hline Critical value & $>0.7$ & $<3$ or $<5$ & $<0.05$ or $<0.08$ & $>0.90$ & $>0.90$ & $>0.90$ & $>0.50$ \\
\hline
\end{tabular}

Note. $\mathrm{N}=324:<3$ (ideal), $<5$ (reasonable), $<0.05$ (ideal), $<0.08$ (reasonable).

\subsection{Basic Statistics and Correlation Analysis}

The descriptive basic statistics (mean, standard deviation) and correlation (pearson correlation) between University teachers' research stress, job satisfaction, emotional intelligence and research performance are shown in Table 2.

The average scientific research pressure of university teachers is 4.21 (full score is 5), which shows that the current research stress load of university teachers is indeed not small, and it is negatively correlated with job satisfaction and scientific research performance. The correlation coefficient is $-0.17(\mathrm{p}<0.01)-0.38(\mathrm{p}<0.01), \mathrm{H} 2$ and $\mathrm{H} 1$ have been preliminarily verified. Job satisfaction and emotional intelligence have no significant correlation, but there is a negative correlation with scientific research performance. In the significant positive correlation $(\mathrm{r}=0.25, \mathrm{P}<0.01), \mathrm{H} 3$ was preliminarily verified; there was a significant positive correlation between emotional intelligence and scientific research performance $(\mathrm{r}=0.33, \mathrm{P}<0.05)$, and $\mathrm{H} 5$ was preliminarily verified. In addition, the correlation coefficients of each variable are less than 0.5 . There is no multiple collinearity problem between the variables. Pearson correlation analysis belongs to the category of descriptive statistics. The correlation coefficient between variables is only a preliminary test of the relationship between each other, but it provides a prerequisite for further testing. 
Table 2. Pearson correlation coefficients of variables

\begin{tabular}{|l|l|l|l|l|l|l|}
\hline & $\begin{array}{l}\text { Mean } \\
\text { value }\end{array}$ & $\begin{array}{l}\text { Standard } \\
\text { deviation }\end{array}$ & 1 & 2 & 3 & 4 \\
\hline Research Pressure & 4.21 & 0.82 & 1 & & & \\
\hline Job satisfaction & 2.32 & 0.75 & $-0.17^{* * *}$ & 1 & & \\
\hline Emotional intelligence & 3.40 & 0.69 & $-0.11^{* *}$ & 0.07 & 1 & \\
\hline Scientific research performance & 3.25 & 0.88 & $-0.38^{* * *}$ & $0.25^{* * *}$ & $0.33^{* *}$ & 1 \\
\hline
\end{tabular}

Note. ${ }^{*}, * *$ and $* * *$ indicate the significance of confidence levels of $0.1,0.05$ and 0.01 , respectively.

\subsection{Regression Analysis of Research Hypothesis Testing}

In hypothesis testing, this paper uses SPSS2.0 statistical software to carry out hierarchical regression analysis of variables. Firstly, the sex, title, age and education of the subjects in the sample are taken as the control variables. Secondly, because the hypothesis involves the test of the direct relationship between variables, three independent variables (research pressure, job satisfaction, emotional intelligence) are established. Among them, research pressure is the antecedent variable. Thirdly, because the research hypothesis involves the test of mediation effect and moderating effect, the research hypothesis will be based on the test of mediation effect and moderating effect. Job satisfaction as a mediating variable was introduced into the regression analysis of research pressure and research performance, while emotional intelligence as a moderating variable was introduced into the regression analysis of research pressure and research performance. The results of regression analysis are shown in Table 3.

Table 3. Hierarchical regression analysis among variables

\begin{tabular}{|c|c|c|c|c|c|c|c|}
\hline & & $\begin{array}{c}\text { MODEL1 } \\
\text { Job } \\
\text { Satisfaction }\end{array}$ & $\begin{array}{c}\text { MODEL2 } \\
\text { Scientific } \\
\text { Research } \\
\text { Performance }\end{array}$ & $\begin{array}{c}\text { MODEL3 } \\
\text { Scientific } \\
\text { Research } \\
\text { Performance }\end{array}$ & $\begin{array}{c}\text { MODEL4 } \\
\text { Scientific } \\
\text { Research } \\
\text { Performance }\end{array}$ & \begin{tabular}{|c|} 
MODEL5 \\
Scientific \\
Research \\
Performance \\
\end{tabular} & $\begin{array}{c}\text { MODEL6 } \\
\text { Scientific } \\
\text { Research } \\
\text { Performance } \\
\end{array}$ \\
\hline \multirow{4}{*}{$\begin{array}{l}\text { Control } \\
\text { variable }\end{array}$} & Gender & 0.04 & 0.06 & 0.05 & 0.04 & 0.07 & 0.05 \\
\hline & Title & $0.11 *$ & $0.21 * *$ & 0.09 & 0.18 & 0.13 & 0.08 \\
\hline & Age & 0.12 & 0.15 & $0.22 * *$ & 0.08 & 0.10 & 0.11 \\
\hline & Education & $0.19 * *$ & 0.23 & $0.25 * *$ & 0.19 & 0.22 & 0.18 \\
\hline \multirow{3}{*}{$\begin{array}{c}\text { Independent } \\
\text { variable }\end{array}$} & Research Pressure & $-0.26 * * *$ & $-0.58 * * *$ & & & $-0.48 * * *$ & \\
\hline & Job satisfaction & & & $-0.31 * *$ & & & \\
\hline & $\begin{array}{c}\text { Emotional } \\
\text { Intelligence }\end{array}$ & & & & $0.42 * * *$ & & \\
\hline $\begin{array}{c}\text { Mediating } \\
\text { variable }\end{array}$ & Job satisfaction & & & & & $0.25 * *$ & \\
\hline \multirow[t]{3}{*}{$\begin{array}{l}\text { Interactive } \\
\text { term of } \\
\text { regulatory } \\
\text { variable } \\
\end{array}$} & $\begin{array}{c}\text { Research Pressure } \\
\boldsymbol{*} \text { Emotional } \\
\text { Intelligence }\end{array}$ & & & & & & $0.35^{* * *}$ \\
\hline & $\mathrm{R} 2$ & $0.18 * *$ & $0.24 * *$ & $0.26 * *$ & $0.31 * * *$ & $0.28 * *$ & $0.31 * *$ \\
\hline & $\Delta \mathrm{R} 2$ & & & & & $0.06 * * *$ & $0.09 * * *$ \\
\hline
\end{tabular}

Note. $*, * *$ and $* * *$ indicate the significance of confidence levels of $0.1,0.05$ and 0.01 , respectively. 
According to Table 3, at the level of control variables, only professional title and education have a significant positive correlation with job satisfaction. The beta coefficients are $0.11(\mathrm{p}<$ 0.1 ) and 0.19 ( $\mathrm{p}<0.05)$, respectively. Gender and age have no significant impact. For scientific research performance, gender in control variables has no significant impact, but title, age and education have a significant impact on scientific research. Performance has a significant impact, the beta coefficient is $0.21(\mathrm{P}<0.05), 0.22(\mathrm{p}<0.05)$ and $0.25(\mathrm{p}<0.05)$, respectively.

In MODEEL, there is a significant negative correlation between scientific research pressure and job satisfaction, and the regression coefficient beta is -0.26 confidence level $\mathrm{P}$ is 0.01 , which indicates that scientific research pressure negatively affects job satisfaction, and the $\mathrm{H} 2$ hypothesis is verified; MODEl2 shows that independent research pressure negatively affects scientific research performance at the confidence level of 0.001 , and the regression coefficient beta is 0.01 . - 0.58, which fully illustrates the negative impact of University teachers' research pressure on the level of scientific research performance, hypothesis H1 validation; MODEI3 is a regression model of University teachers' job satisfaction and scientific research performance, the numerical results show that job satisfaction positively affects the level of University teachers' scientific research performance $(\mathrm{B}=0.31, \mathrm{P}<0.05)$ verify hypothesis H3; MODEI3 is a regression model of University teachers' job satisfaction and scientific research performance. Emotional intelligence of university teachers can effectively and positively affect the level of scientific research performance $(\mathrm{B}=0.42, \mathrm{P}<$ $0.01)$, and H5 has been verified.

In order to further explore the relationship between University teachers' research pressure and research performance, this paper analyses whether there are other variables that affect the relationship between them indirectly except the direct impact between them. These indirect variables can strengthen or weaken the influence between independent variables and dependent variables. According to Baron and Kenny, variables can be divided into mediating variables and adjusting variables according to their roles between independent variables and dependent variables. In view of this, this paper introduces job satisfaction as a mediating variable and emotional intelligence as a moderating variable into the regression analysis.

What conditions should a variable satisfy in order to become a mediating variable in the relationship between independent variables and dependent variables? According to Wen Zhonglin and others, the following four conditions need to be satisfied: first, the independent variables are significantly related to dependent variables; second, the independent variables must significantly affect mediating variables; third, the mediating variables have a significant impact on dependent variables; fourth, the mediating variables are significantly affected by mediating variables. Quantity will weaken or eliminate the influence of independent variables on dependent variables. According to the previous analysis, condition one has been met, and now focus on the analysis of whether condition four can be established. For this reason, in MODEL 5, we put scientific research pressure and job satisfaction into regression analysis to predict University teachers' scientific research performance. The results show that the discriminant coefficient R2 is increased from 0.26 to $0.28(\mathrm{p}<0.05)$, which indicates that the effect of regression analysis is optimized and the influence of teachers' job satisfaction on 
scientific research performance is weakened (the beta coefficient is 0.31 ). Change to 0.25 ). This result is precisely because scientific research pressure exerts a negative effect on scientific research performance through the intermediary of job satisfaction, which partly weakens the positive effect of job satisfaction on scientific research performance, thus fully demonstrating the intermediary effect of job satisfaction between University teachers' scientific research pressure and scientific research performance. Verification has been made.

In hierarchical regression analysis, MODEL6 is used to test the moderating effect of emotional intelligence on University teachers' scientific research pressure and scientific research performance. We put the product of scientific research pressure and emotional intelligence into the regression equation as a moderating variable to predict the level of scientific research performance. The results show that the interaction term of moderating variables has a positive impact on the level of scientific research performance. The level of scientific research performance $(\mathrm{B}=0.35, \mathrm{P}<0.01)$, and the adjusted discriminant coefficient (R) is 0.09 ( $p<0.01)$, that is, the explanatory degree of variance variation is $9 \%$. This shows that emotional intelligence can significantly regulate the relationship between University teachers' research pressure and research performance, and H6 has been verified.

\section{Research Conclusions and Suggestions}

\subsection{The Conclusions of This Study}

By introducing job satisfaction and emotional intelligence as mediating variables and moderating variables respectively, this paper, based on questionnaire survey and data statistics, deeply explores the influencing mechanism between University teachers' scientific research pressure and scientific research performance, and draws the following conclusions:

1). At present, university teachers in China are under great pressure of scientific research. This conclusion is also consistent with the relevant research conclusions. In fact, whether it is 985,211 universities or ordinary universities, scientific research performance has become one of the important indicators to measure the development and progress of schools. Because "a University can't pass all kinds of evaluations without scientific research achievements, and it can't get the relevant policies and funds, so it loses the opportunity of development". Therefore, all kinds of universities attach great importance to the performance appraisal of scientific research. Although the specific forms of the appraisal are slightly different, it is basically inseparable from the contents of scientific research projects, funds, papers, awards and other appraisals. It is precisely these appraisals that bring great pressure to university teachers.

2). Recently, the research pressure on university teachers will have a negative impact on the overall research performance. Admittedly, pressure is not all unfavorable, moderate pressure is even an important factor to improve job performance, but the current research pressure on university teachers has exceeded the scope of "moderate", which will have a certain negative impact on scientific research performance. Firstly, the long-term excessive pressure will frustrate the enthusiasm of scientific research work and make scientific research appear "fault" phenomenon on the individual teachers; secondly, higher scientific research pressure 
will easily make teachers' scientific research work tend to be "utilitarian" and "light weight" and other tendencies, leading to academic mediocrity and even some academic misconduct phenomenon.

3). University teachers' research pressure negatively affects research performance through job satisfaction intermediary. In other words, the impact of research pressure on research performance is not always linear, there is an intermediary variable between them. On the one hand, scientific research pressure will reduce teachers' job satisfaction, and "has a certain predictive effect on job satisfaction, that is, the greater the pressure, the lower the job satisfaction". On the other hand, the decline of teachers' job satisfaction is prone to cause job burnout and work motivation weakening, which has a negative impact on scientific research performance.

4). Emotional intelligence can effectively and positively regulate the impact of scientific research pressure on scientific research performance. In the face of pressure, emotional intelligence, as an important personality psychological characteristic, can effectively change teachers' individual response to pressure, weaken or eliminate the adverse reactions and negative interference caused by pressure, and even make the relationship between pressure and performance change from negative to positive, that is to say, pressure is transformed into motivation and scientific research performance is improved.

\subsection{Some Countermeasures and Suggestions}

This study not only theoretically clarifies the mechanism of the influence of University teachers' research pressure and research performance, but also has guiding value for the current reform of university scientific research management practice.

1). Reduce the stressors of university teachers and avoid overlapping research and other work stressors. Many studies have confirmed that scientific research pressure ranks first among university teachers' work pressure, but if the work pressure from other aspects overlaps with scientific research pressure, it will invisibly increase teachers' sense of scientific research pressure, making the already overburdened sense of scientific research pressure more serious. Therefore, university administrators should formulate corresponding policies to minimize teachers' stressors, especially to avoid the double burden of teaching tasks and research pressures.

2). Reconstruct or optimize the scientific research assessment system to keep the scientific research pressure within the "moderate" range. At present, the scientific research pressure of university teachers mainly comes from the too strict scientific research performance appraisal system. Many universities have not carefully studied the actual situation of the university, but copy the assessment system of other universities and put forward the "high, big and top" assessment criteria. The result is just the opposite. In fact, the establishment of a university's scientific research assessment system should take into account the following factors: first, the basic number of teachers' scientific research ability; second, taking into account the "quality" and "quantity" of scientific research achievements; third, the requirements of school teaching tasks; fourth, the needs of discipline and professional development. The four factors 
mentioned above should be considered comprehensively, and the scientific research assessment system should be reconstructed or optimized so that teachers' scientific research pressure is in a "moderate" state. Recently, the Ministry of Science and Technology, the Ministry of Education and other five departments jointly issued a notice on the special action of cleaning up the "Four Ways" (only papers, only professional titles, only academic qualifications, only awards). If it can be implemented, it may have a positive effect on reducing teachers' research pressure.

3). Improve teachers' salary and pay, and improve teachers' job satisfaction. It is found that the increase of scientific research pressure will reduce teachers' job satisfaction, which will negatively affect scientific research performance. Therefore, while increasing the pressure of teachers' scientific research, schools should improve teachers' job satisfaction through various ways and give full play to the incentive function of teachers' job satisfaction. Teachers' job satisfaction comes from many aspects, among which the most important and stimulating value is the salary and treatment of teachers. Through research, Li Chong and Zhang Li found that 'improving teachers' salary and salary and optimizing salary structure can effectively improve teachers' personal job satisfaction, and have a high incentive value for scientific research performance."

4). Pay attention to teachers' emotional world and cultivate teachers' emotional intelligence. This study confirms that teachers with high emotional intelligence can reduce or eliminate the negative impact of scientific research pressure on scientific research performance, which indicates that in the current high-pressure environment of scientific research, the cultivation of emotional intelligence is an effective way to improve scientific research performance. However, whether in the process of talent introduction or teacher training, universities focus on traditional intelligence, ignoring teachers' emotional world and emotional power. Therefore, universities should take corresponding measures to cultivate teachers' emotional intelligence. Firstly, provide various forms of training activities, which are related to education and teaching as far as possible. Through theoretical cognition and skill learning, teachers can gradually improve their emotional intelligence in practice. Secondly, bring emotional intelligence training into the scope of teachers' professional development and form institutionalization and standardization. Schools can regularly assess and make corresponding improvements through psychological measurement. Teachers should be encouraged to form a sense of self-improvement of emotional intelligence, to study actively and to cultivate consciously, and to place emotional intelligence on the same important position as traditional intelligence.

\section{References}

Baron, R. M., \& Kenny, D. A. (1986). The moderator-mediator variable distinction in social psychological research: Conceptual, strategie, and statistical considerations. Journal of $\begin{array}{llll}\text { Personality and Social } & \text { Psychology, } & \text { 117-123. }\end{array}$ https://doi.org/10.1037/0022-3514.51.6.1173

Boudreaux, E., \& Brantley, P. J. (2012). Stress, Job Satisfaction, Coping and Psychological Distress Among Emergency Medical. Medical Technicians Prehospital and Disaster 
Medicine, 2012(12), 242-249.

Chong, L., Li, Z., \& Yongjian, S. (2016). An Empirical Study on the Relationship between Salary Structure, Job Satisfaction and University Teachers' Job Performance. Fudan Education Forum, (5).

Ciarrochi, J. V., Chan, A. Y. C., \& Caputi, P. (2000). A critical evaluation of the emotional intelligence construct. Personality and Individual Differ-es, 28(3), 539-56. https://doi.org/10.1016/S0191-8869(99)00119-1

Gilboa, S., Shirom, A., Fried, Y., \& Cooper, C. (2008). A meta-analysis of work demand stressors and job performance: Examinning main and moderating effects. Personnel Psychology, 61(2), 227-271. https://doi.org/10.1111/j.1744-6570.2008.00113.x

Huihua, Z., \& Hui, W. (2011). A Meta-analysis of the Relationship between Individual Emotional Intelligence and Workplace Performance. Journal of Psychology, (2).

King, M., \& Garner, D. (2016). Emotional intelligence and occupational stress among professional staff in New Zealand. International Journal of Organizational Analysis, 14(3), 186-203. https://doi.org/10.1108/19348830610823392

LadahI, T. M., \& Kejner, M. (2015). The definition and measurement of job involvement. Journal of Applied Psychology, 49(1), 24. https://doi.org/10.1037/h0021692

Robert, M. L. D. (2015). Guidelines for the Design and Evaluation of Courses and Curriculum Systems (p. 12). Hangzhou: Zhejiang University Press.

Shifang, Z. (2017). What is Education (p. 150). Beijing: Life-Reading·Xinzhi Bookstore.

The Connotation and Basic Characteristics of Yangling and Bi Xianshun's "Double-Class" Construction. University Education Science, No. 4, 2017.

Trum, S, \& Hara, L. A. (2016). Relation of employee and manger emotional interlligence to job satisfaction and performance. Journal of Vocational Behavior, (68), A461-473. https://doi.org/10.1016/j.jvb.2005.10.003

Xiaodong, X. (2014). The Work Stress and Job Satisfaction Status of Knowledge Workers and Their Relationships. Applied Psychology, (3).

Xiaoli, J., \& Fengwen, C. (2018). The Mechanism of Work Stress on the Performance of University Teachers' Work Performance. Statistics and Decisions, 16.

Xin, P., Jian, W., \& Zijian, Z. (2010). Analysis of the Factors Affecting the Work Stress of College Teachers in Shaanxi on Mental Health. Journal of Chinese Journal of Health Psychology, (1).

Xinling, L. (2005). The pressure of scientific research for college teachers is great, and teaching loses professional passion. Retrieved from http://www.lugou.con.cn/news/20050921.shtml

Zhonglin, W., \& Jietai, H. (2005). Comparison and Application of Regulating Effect and 


\section{Macrothink \\ International Journal of Management Innovation Systems \\ ISSN 1943-1384 2019, Vol. 4, No. 1}

Mediation Effect. Journal of Psychology, (3).

\section{Copyright Disclaimer}

Copyright for this article is retained by the author(s), with first publication rights granted to the journal.

This is an open-access article distributed under the terms and conditions of the Creative Commons Attribution license (http://creativecommons.org/licenses/by/3.0/). 